\title{
Interactive comment on "Effects of grass leaf anatomy, development and light/dark alternation on the triple oxygen isotope signature of leaf water and phytoliths: insights for a new proxy of continental atmospheric humidity" by Anne Alexandre et al.
}

\section{Anonymous Referee \#1}

Received and published: 24 April 2019

The reviewed manuscript presents an important work, which examines the robustness of the 170-excess of phytoliths as a proxy for $\mathrm{RH}$. However, more work is needed to make the manuscript more readable. At the present form, I had troubles even verifying that the main conclusion are supported by the data. Moreover, I am not sure if there are quantitative conclusions, as vague terms like "most" are used throughout the text. Some detailed comments appear below.

Printer-friendly version

Discussion paper 
Tables 1 and 2, contains full details of the results, and as such are hard to follow. So additional figures and summary tables are needed for easier access to the data (and then the full data can be moved to an appendix). Figure 2 should be divided into four different figures, each with its own caption. Will be good to explain in the caption what the filled versus empty markers stand for (this is also not explained in the legend). Figure 2a, correct the Y-axis.

The second half of the abstract needs to be made clearer. Start with: Lines 29 and 31: "most" - give percentage. Line 32: "at that time" - replace with "during this growth phase" for clarity Line 33 - Replace "At least", by "when RH was fixed during day/night" " However, when day/night alternations are characterized by significant changes in $\mathrm{RH}$, the lowest $\mathrm{RH}$ conditions favoring evaporation and silica polymerization should be considered when calibrating the phytolith proxy." - Not clear. Do you mean the proxy is for the minimum diurnal $\mathrm{RH}$ ? Also maybe need to add here what is the percentage of silica polymerization that happens under the lowest $\mathrm{RH}$ conditions.

The last sentence of the abstract should be removed or rewritten.

Section 2: The authors give there two different definition for theta. Since they are not identical, one of them must be wrong. Indeed the second one is the definition for lambda (or slope) which they give later. Papers cited by the authors give these definitions: 1) Angert, A., Cappa, C.D., DePaolo, D.J.: Kinetic O-17 effects in the hydrologic cycle: Indirect evidence and implications. Geochim. Cosmochim. Acta 68, 3487-3495, 2004. 2) Luz, B., Barkan, E.: Variations of 170/160 and $180 / 160$ in meteoric waters. Geochim. Cosmochim. Acta 74, 6276-6286. https://doi.org/10.1016/j.gca.2010.08.016, 2010. Please correct. Also in Line 117, a reference line is defined not only by slope, but also by a point it is going through - add this info.

Line 287 - " Isotope data from experiment 2b (Table 2) shows that D'18OPhyto-IW and 170 excessPhyto-IW values obtained for the same tank are very close when constant

Printer-friendly version

Discussion paper

\section{.}


day conditions of light,temperature and $\mathrm{RH}$ or when day/night alternation conditions are set." - This seems to contradict what appear in the abstract? So which one is correct? Do day/night variations in $\mathrm{RH}$ have an effect or not? Also, throughout the results, please don't just use the terms "very close" without giving the numbers, or indicating if the difference is significant or not.

Line 374 - If it is only "52\%", why this will dominate the signal? Line 399 - "mainly occur" - give a number. Line 414 Quantify "most" and point to a figure or reference showing this. Line 426 - "Likely Favor"? - Still not clear to me. So what is the 170excess of phytoliths actually tell us? If the bottom line of this study is that more research is needed to answer this question, then this should be clearly written in the abstract and conclusions.

Interactive comment on Biogeosciences Discuss., https://doi.org/10.5194/bg-2019-73, 2019. 